\title{
Selective endothelin-1 receptor type A inhibition in subjects undergoing cardiac surgery with preexisting left ventricular dysfunction: Influence on early postoperative hemodynamics
}

\author{
John M. Toole, MD, ${ }^{\mathrm{a}, \mathrm{b}}$ John S. Ikonomidis, MD, PhD, ${ }^{\mathrm{a}, \mathrm{b}}$ Wilson Y. Szeto, $\mathrm{MD},{ }^{\mathrm{c}}$ James L. Zellner, MD, ${ }^{\mathrm{d}}$ \\ John Mulcahy, BA, ${ }^{\text {a,b }}$ Rachael L. Deardorff, BS, ${ }^{\mathrm{a}, \mathrm{b}}$ and Francis G. Spinale, MD, PhD ${ }^{\mathrm{a}, \mathrm{b}}$,
}

\begin{abstract}
Objective: A robust release of endothelin-1 with subsequent endothelin-A subtype receptor activation occurs in patients after cardiac surgery requiring cardiopulmonary bypass. Increased endothelin-A subtype receptor activation has been identified in patients with poor left ventricular function (reduced ejection fraction). Accordingly, this study tested the hypothesis that a selective endothelin-A subtype receptor antagonist administered perioperatively would favorably affect post-cardiopulmonary bypass hemodynamic profiles in patients with a preexisting poor left ventricular ejection fraction.
\end{abstract}

\begin{abstract}
Methods: Patients $(\mathrm{n}=29 ; 66 \pm 2$ years) with a reduced left ventricular ejection fraction $(37 \% \pm 2 \%)$ were prospectively randomized in a blinded fashion, at the time of elective coronary revascularization or valve replacement requiring cardiopulmonary bypass, to infusion of the highly selective and potent endothelin-A subtype receptor antagonist sitaxsentan at 1 or $2 \mathrm{mg} / \mathrm{kg}$ (intravenous bolus; $\mathrm{n}=9,10$ respectively) or vehicle (saline; $\mathrm{n}=10$ ). Infusion of the endothelin-A subtype receptor antagonist/vehicle was performed immediately before separation from cardiopulmonary bypass and again at 12 hours after cardiopulmonary bypass. Endothelin and hemodynamic measurements were performed at baseline, at separation from cardiopulmonary bypass (time 0 ), and at 0.5 , 6,12 , and 24 hours after cardiopulmonary bypass.
\end{abstract}

Results: Baseline plasma endothelin $(4.0 \pm 0.3 \mathrm{fmol} / \mathrm{mL})$ was identical across all 3 groups, but when compared with preoperative values, baseline values obtained from age-matched subjects with a normal left ventricular ejection fraction $(\mathrm{n}=37$; left ventricular ejection fraction $>50 \%)$ were significantly increased $(2.9 \pm 0.2 \mathrm{fmol} / \mathrm{mL}$, $P<.05)$. Baseline systemic $\left(1358 \pm 83\right.$ dynes $\left./ \mathrm{sec} / \mathrm{cm}^{-5}\right)$ and pulmonary $\left(180 \pm 23 \mathrm{dynes} / \mathrm{sec} / \mathrm{cm}^{-5}\right)$ vascular resistance were equivalent in all 3 groups. As a function of time 0 , systemic vascular resistance changed in an equivalent fashion in the post-cardiopulmonary bypass period, but a significant endothelin-A subtype receptor antagonist effect was observed for pulmonary vascular resistance (analysis of variance; $P<.05$ ). For example, at 24 hours post-cardiopulmonary bypass, pulmonary vascular resistance increased by 40 dynes $/ \mathrm{sec} / \mathrm{cm}^{-5}$ in the vehicle group but directionally decreased by more than 40 dynes $/ \mathrm{sec} / \mathrm{cm}^{-5}$ in the $2 \mathrm{mg} / \mathrm{kg}$ endothelin-A subtype receptor antagonist group $(P<.05)$. Total adverse events were equivalently distributed across the endothelinA subtype receptor antagonist/placebo groups.

Conclusion: These unique findings demonstrated that infusion of an endothelin-A subtype receptor antagonist in high-risk patients undergoing cardiac surgery was not associated with significant hemodynamic compromise. Moreover, the endothelin-A subtype receptor antagonist favorably affected pulmonary vascular resistance in the early postoperative period. Thus, the endothelin-A subtype receptor serves as a potential pharmacologic target for improving outcomes after cardiac surgery in patients with compromised left ventricular function. ( $\mathrm{J}$ Thorac Cardiovasc Surg 2010;139:646-54)

Cardiopulmonary bypass (CBP) remains a mainstay for the performance of cardiac surgical procedures, including coronary artery bypass grafting $(\mathrm{CABG})$ and valve replacement. After separation from $\mathrm{CPB}$, significant neurohormonal sys-

From the Medical University of South Carolina, ${ }^{\text {a }}$ Charleston, SC; Ralph H. Johnson VA Medical Center, ${ }^{\text {b }}$ Charleston, SC; University of Pennsylvania, ${ }^{\mathrm{c}}$ Philadelphia, $\mathrm{Pa}$; and University of Tennessee at Chattanooga, ${ }^{\mathrm{d}}$ Chattanooga, Tenn.

Disclosures: None.

This study was supported by an unrestricted research grant from Encysive Pharmaceuticals, which was acquired by Pfizer Inc in June 2008, National Institutes of Health grant HL87134, and a Merit Award from the Veterans' Affairs Health Administration.

Presented at the 35th Annual Meeting of the Western Thoracic Surgical Association, June 27, 2009, Banff, Canada. tem activation and the release of bioactive molecules invariably occur and can continue well into the postoperative period. Specifically, increased release of the bioactive molecule endothelin (ET)-1 has been documented in the early

Received for publication June 10, 2009; revisions received Nov 13, 2009; accepted for publication Nov 22, 2009; available ahead of print Jan 14, 2010.

Address for reprints: Francis G. Spinale, MD, PhD, Cardiothoracic Surgery, Strom

Thurmond Research Center, 114 Doughty St, Suite 625, Charleston, SC 29425

(E-mail: wilburnm@musc.edu).

$0022-5223 / \$ 36.00$

Copyright (C) 2010 by The American Association for Thoracic Surgery

doi:10.1016/j.jtcvs.2009.11.046 


$$
\begin{aligned}
& \text { Abbreviations and Acronyms } \\
& \begin{aligned}
\mathrm{AE} & =\text { adverse event } \\
\mathrm{ANOVA} & =\text { analysis of variance } \\
\mathrm{CABG} & =\text { coronary artery bypass grafting } \\
\mathrm{CPB} & =\text { cardiopulmonary bypass } \\
\mathrm{ET} & =\text { endothelin } \\
\mathrm{ET}-\mathrm{ARA} & =\text { endothelin-A receptor antagonist } \\
\mathrm{LV} & =\text { left ventricular } \\
\mathrm{RV} & =\text { right ventricular } \\
\mathrm{SAE} & =\text { serious adverse event }
\end{aligned}
\end{aligned}
$$

post-CPB period and can affect important determinants of postoperative recovery, such as systemic, pulmonary, and coronary conduit vascular tone. ${ }^{1-8}$ More complex CABG procedures (eg, repeat revascularization and concomitant valve repair/replacement) and preexisting comorbidities (eg, increased age and left ventricular [LV] systolic dysfunction) in patients have been associated with increased risk for a complex postoperative course. ${ }^{9-15}$ However, the mechanistic relationship between ET receptor signaling and early postoperative hemodynamics, particularly in patients with preexisting LV dysfunction, has not been examined. Accordingly, the overall goal of this study was to examine the early postoperative indices of systemic and pulmonary vascular resistance after administration of an ET receptor in older patients who have preexisting LV dysfunction and are undergoing CABG, valve replacement, or combined procedures requiring $\mathrm{CPB}$.

ET mediates several biologic and physiologic responses through 2 primary receptor subtypes: the ET-A and B receptors. ${ }^{4-8}$ In past studies, nonselective ET receptor antagonists (those that inhibit ET binding to both the ET-A and B receptors) have been used in several cardiovascular disease states, including systemic arterial hypertension, and in patients with compromised LV function. ${ }^{1,2,16-19}$ However, outcomes from the use of these nonselective ET receptor antagonists, particularly in patients with reduced LV systolic dysfunction, were equivocal or actually worsened clinical status. ${ }^{16-19}$ These past results were likely due, at least in part, to the distinctly different receptor transduction pathways inherent to the ET-A and B receptors. Specifically, ET-A receptor activation causes increased activation of certain protein kinase-C isoforms, which in turn mobilizes calcium and ultimately vascular smooth muscle vasoconstriction. ${ }^{4,6}$ In addition, ET-A receptor activation has been shown to exacerbate myocyte contractile dysfunction after simulated cardioplegic arrest. $^{20}$ In contradistinction, ET-B receptor activation is coupled to nitric oxide synthesis pathways, which will in turn promote vascular smooth muscle relaxation, particularly in the pulmonary vasculature. ${ }^{5,7}$ Moreover, the ET-B receptor binds circulating ET within the pulmonary circuit and thereby forms an important clearance pathway for this bioactive peptide. ${ }^{21}$ Taken together, this would suggest that selective ET-A receptor inhibition in which the ET-B receptor remains unopposed would be of potential hemodynamic benefit. Accordingly, highly selective ET-A receptor antagonists (ET-ARAs) have been developed. One prototypical, highly selective (6500:1, ET-A vs ET-B) and potent $(\mathrm{Ki}=0.43 \mathrm{nM})$ ET-ARA is sitaxsentan, which has been used in oral formulation in patients with pulmonary arterial hypertension. ${ }^{22,23}$ In a recently completed dose-ranging study by this laboratory, an intravenous formulation of this ET-ARA was safely administered to patients after CABG and CPB. ${ }^{24,25}$ However, this past study was performed in patients with minimal comorbidities and normal LV function. Accordingly, the present study was performed with 2 specific aims: (1) evaluate the effects of intravenous administration of a selective ET-ARA in older patients with preexisting LV systolic dysfunction in the post-CPB period with respect to overall safety and hemodynamic stability, and (2) examine whether and to what degree ET-ARA administration affected systemic and pulmonary vascular resistance properties in the post-CPB period, in this particular group of patients.

\section{MATERIALS AND METHODS \\ Patients}

After approval by the Human Subjects Review Committee of the Medical University of South Carolina (HR16252), patients undergoing $\mathrm{CABG}$, aortic or mitral valve replacement, or combined $\mathrm{CABG}$ and valve procedures requiring $\mathrm{CPB}$ were initially evaluated for study eligibility. The inclusion criteria were age more than 60 years and an LV ejection fraction of less than $50 \%$ documented by a preoperative echocardiogram; diabetic patients were to have a fasting glucose less than $350 \mathrm{mg} / \mathrm{dL}$ or recent hemoglobin A1c level less than $9 \%$, or if hypertensive, be on a stable medical regimen with no significant changes during the past 30 days. Although the study was conducted at several institutions, a larger proportion of patients were recruited from the Ralph H. Johnson Veterans Affairs Medical Center, which resulted in a larger number of male patients eligible for enrollment. The exclusion criteria included emergency revascularization, stroke or thromboembolic event within 3 months before surgery, recent $(<7$ days) myocardial infarction, documented coagulopathy, or hepatic dysfunction as defined by aspartate transaminase or alanine transaminase more than 1.5 times the upper limit of normal. If the patient met these criteria, informed consent was obtained.

\section{Operative Procedure}

Standard induction and maintenance of anesthesia were accomplished with a combination of sufentanil, midazolam, and isoflurane. Appropriate monitoring lines (radial artery and pulmonary artery catheters) were placed. Before CPB, systemic heparinization was accomplished with a heparin dose of $400 \mathrm{U} / \mathrm{kg}$. Additional heparin was administered during CPB to maintain an activated clotting time of more than 400 seconds. CPB was maintained at a cardiac index of 2.0 to $2.4 \mathrm{~L} / \mathrm{min} / \mathrm{m}^{2}$ with a Stockert-Shiley roller pump (Shiley Inc, Irvine, Calif) using a Sarns membrane oxygenator (Terumo/Sarns, Ann Arbor, Mich). The pump prime consisted of $1200 \mathrm{~mL}$ of normothermic, lactated Ringer's solution, to which $500 \mathrm{~mL}$ of hetastarch, 25 meq of sodium bicarbonate, and 1000 units of heparin were added; however, retrograde autologous priming was performed whenever possible before initiation of $\mathrm{CPB}$. Initial cardioplegic arrest was 
accomplished with antegrade normothermic administration of 250 to 500 $\mathrm{mL}$ of a solution of $\mathrm{D}_{5} / 0.2 \mathrm{NaCL}$ containing $29 \mathrm{~mL}$ of tromethamine buffer, $34 \mathrm{~mL}$ of adenosine citrate phosphate dextrose, and $60 \mathrm{meq}$ of KCL $(120 \mathrm{meq} / \mathrm{L})$ in a 4:1 blood:crystalloid mixture. This was followed immediately with retrograde administration of $1000 \mathrm{~mL}$ of hypothermic cardioplegic solution. Every 20 minutes cardioplegic arrest was maintained with 250 to $500 \mathrm{~mL}$ retrograde administration of the cardioplegic solution with a reduced potassium concentration $(60 \mathrm{meq} / \mathrm{L})$, and a $500 \mathrm{~mL}$ terminal normothermic cardioplegic shot was given before crossclamp removal. Patients were not actively cooled while on CPB and were rewarmed to a rectal temperature of $36.5^{\circ} \mathrm{C}$ before separation. At the termination of $\mathrm{CPB}$, heparin was neutralized with protamine in a 1:1 ratio. Nitroglycerin infusion was administered postoperatively for systemic hypertension (defined as a $20 \%$ increase over preoperative levels) and ST segment elevation or depression of greater than $1 \mathrm{~mm}$. Epinephrine infusion was administered postoperatively to maintain a cardiac index of greater than $2.0 \mathrm{~L} / \mathrm{min} / \mathrm{m}^{2}$ when needed. Discharge criteria from the intensive care unit included complete weaning from all vasoactive and inotropic infusions, extubation without pulmonary support, and no evidence of major organ failure. Discharge criteria from the hospital included stable sinus rhythm, no supplemental oxygen requirement, ambulation, normal bowel and bladder function, and tolerance of oral intake.

\section{Endothelin-1-A Receptor Antagonist}

The ET-ARA used in this study was sitaxsentan sodium (TBC11251Na), which has been described. ${ }^{22-26}$ This study was performed under Food and Drug Administration Investigational New Drug 52,527. It has been demonstrated that this ET-ARA quickly reaches a steady-state level (within 30 minutes) after intravenous administration and has a half-life of approximately 6 hours. ${ }^{22,26}$ Sitaxsentan has been safely used in patients with primary pulmonary hypertension. ${ }^{22,23}$ More recently, we demonstrated that intravenous sitaxsentan can be safely administered to patients undergoing elective CABG and CPB with no preexisting risk factors. ${ }^{24,25}$ Moreover, these past studies demonstrated that both 1 and $2 \mathrm{mg} / \mathrm{kg}$ infusion doses influenced both pulmonary hemodynamics and bioactive signaling. On the basis of these past results, the present study used a 1 and $2 \mathrm{mg} / \mathrm{kg}$ ET-ARA infusion protocol that was formulated in sterile saline within 2 hours of systemic infusion. The vehicle for this study was an equal volume of sterile saline.

\section{Study Protocol}

After informed consent, 29 patients were randomized to the following 3 treatment groups using a predetermined randomization coding scheme that was developed before the initiation of the study and maintained in a blinded fashion by the study coordinator (J.M.): (1) vehicle (saline vehicle bolus); (2) $1 \mathrm{mg} / \mathrm{kg}$ of ET-ARA; and (3) $2 \mathrm{mg} / \mathrm{kg}$ of ET-A antagonist. The vehicle or ET-ARA was infused immediately at separation from CPB as a bolus infusion over 5 minutes and then again at 12 hours post-CPB. The initial time point of infusion, which corresponded to when the infusion was complete and the patient was removed from $\mathrm{CPB}$, was designated as time 0 . With this as the reference, the following time points were used: baseline (after placement of arterial and pulmonary catheters, but before the onset of $\mathrm{CPB}$ ), time 0 (immediately at cessation of $\mathrm{CPB}$ and after placebo/drug infusion), 0.5 hours post-CPB, 6 hours post-CPB, 12 hours post-CPB, and 24 hours post-CPB. The hemodynamic measurements obtained and computed at each of these time points were heart rate, mean arterial pressure, mean pulmonary artery pressure, cardiac output, systemic vascular resistance, and pulmonary vascular resistance. At the designated time points, blood samples were collected to determine plasma ET using radioimmunoassay methods well described by this laboratory. ${ }^{3,24,25}$ In addition, plasma concentrations of the ET-ARA sitaxsentan were determined by a precalibrated high-performance liquid chromatography method described previously. ${ }^{26}$ In the postoperative period, inotropic and vasodilator requirements were recorded. All adverse events (AEs) were adjudicated, reviewed, and reported to the Medical University of South Carolina Institutional Review Board.
TABLE 1. Preoperative demographics and perioperative variables for patients randomized to vehicle or endothelin-A receptor antagonist sitaxsentan

\begin{tabular}{lcccc}
\hline & & \multicolumn{2}{c}{ ET-ARA } & \\
\cline { 3 - 4 } & Vehicle & $\mathbf{1 m g / k g}$ & $\mathbf{2 m g / k g}$ & $P$ value \\
\hline Preoperative & & & & \\
Age (y) & $67 \pm 2$ & $62 \pm 3$ & $68 \pm 3$ & .242 \\
LVEF (\%) & $35 \pm 3$ & $38 \pm 2$ & $37 \pm 3$ & .762 \\
Hypertensive (n) & $9 / 10$ & $6 / 9$ & $8 / 10$ & .273 \\
Diabetic (n) & $7 / 10$ & $4 / 9$ & $6 / 10$ & .483 \\
Gender (M/F) & $9 / 1$ & $7 / 2$ & $10 / 0$ & .283 \\
CABG only (n) & $7 / 10$ & $8 / 9$ & $7 / 10$ & .546 \\
Valve replacement (n) & $1 / 10$ & $0 / 9$ & $0 / 10$ & .374 \\
CABG valve (n) & $2 / 10$ & $1 / 9$ & $3 / 10$ & .596 \\
Diuretics (n) & $3 / 10$ & $1 / 9$ & $7 / 10$ & .025 \\
Reoperation(n) & $0 / 10$ & $1 / 9$ & $4 / 10$ & .051 \\
Plasma ET (fmol/mL) & $3.9 \pm 0.4$ & $3.7 \pm 0.3$ & $4.3 \pm 0.7$ & .786 \\
Intraoperative & & & & \\
Crossclamp time (min) & $74 \pm 12$ & $88 \pm 10$ & $75 \pm 4$ & .488 \\
CPB time (min) & $103 \pm 16$ & $101 \pm 9$ & $107 \pm 10$ & .921 \\
Postoperative & & & & \\
Intubation time (h) & $23 \pm 3$ & $24 \pm 8$ & $32 \pm 13$ & .689 \\
ICU time (d) & $6 \pm 1$ & $5 \pm 1$ & $10 \pm 3$ & .183 \\
Length of stay (d) & $10 \pm 1$ & $11 \pm 3$ & $17 \pm 4$ & .239 \\
\hline LVEF Left ventictannn
\end{tabular}

$\overline{L V E F}$, Left ventricular ejection fraction; $C A B G$, coronary artery bypass grafting; $E T$, endothelin; $E T-A R A$, endothelin-A receptor antagonist; $C P B$, cardiopulmonary bypass; $I C U$, intensive care unit. Vehicle $\mathrm{n}=10,1 \mathrm{mg} / \mathrm{kg} \mathrm{n}=9,2 \mathrm{mg} / \mathrm{kg} \mathrm{n}=10$.

\section{Data Analysis}

Hemodynamic parameters and plasma ET-1 levels at each time point were evaluated with a multiway analysis of variance (ANOVA). If the ANOVA revealed significant differences, pairwise tests of individual group means were compared by adjusted probabilities (Bonferroni method). Categoric variables, such as demographics and preoperative variables, were examined by chi-square analysis. Changes in pulmonary and systemic vascular resistance were computed as follows. First, the absolute values at baseline and the designated time points were examined by ANOVA. Second, the change in the main response variables, such as systemic and pulmonary vascular resistance, was examined as a function from time 0 because this was the index time point for this study with respect to treatment and separation from CPB. Next, pairwise comparisons in the changes in these parameters were performed using adjusted probabilities. All statistical procedures were performed using STATA statistical software (STATA Intercooled V 8.0.; StataCorp LP, College Station, Tex). Results are presented as mean \pm standard error of the mean.

\section{RESULTS}

Demographic, intraoperative, and postoperative descriptive data for the 29 patients enrolled in this study are presented in Table 1. The main preoperative risk variables of interest, age, and LV ejection fraction were equivalent across the patients randomized to the vehicle and 1 and 2 $\mathrm{mg} / \mathrm{kg}$ ET-ARA groups. All other preoperative data were similar across groups with the exception of the number of patients presenting for a reoperation (all a secondary revascularization procedure, $>1$ year from previous procedure) and diuretic use, in which a higher number of these patients were randomized to the $2 \mathrm{mg} / \mathrm{kg}$ group. Baseline plasma ET 


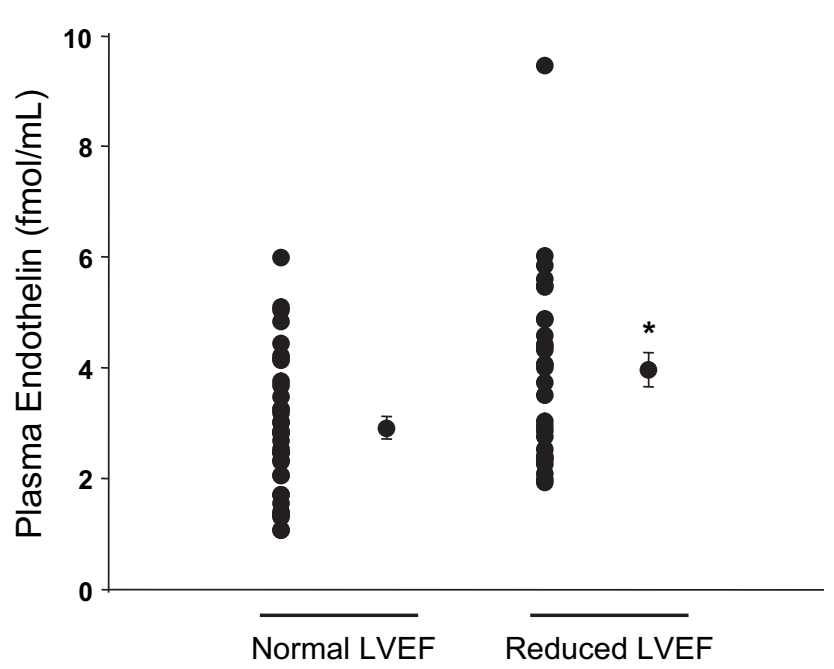

FIGURE 1. Preoperative (baseline) plasma ET-1 values were determined in patients with a normal LVEF $(n=37$, defined as $>50 \%)$ undergoing elective cardiac surgery from a study recently performed using identical high-sensitivity immunoassay procedures ${ }^{24}$ and compared with baseline plasma ET values obtained from the present study in patients with a reduced LVEF $(n=29,<50 \%)$. The distribution of individual values from these 2 patient groups is shown, where the mean baseline ET level was $2.9 \pm 0.2$ $\mathrm{fmol} / \mathrm{mL}$ in the normal LVEF group and was significantly increased in patients with reduced LVEF $(4.0 \pm 0.2 \mathrm{fmol} / \mathrm{mL}, * P<.05)$. $L V E F$, Left ventricular ejection fraction.

levels were equivalent across all 3 treatment groups. However, when the composite baseline plasma ET levels were compared with previously obtained preoperative ET levels in patients undergoing elective $\mathrm{CABG}$ with a normal $\mathrm{LV}$ ejection fraction, ${ }^{24}$ the baseline ET levels obtained in the present study were significantly higher (Figure 1). Aortic crossclamp time and total CPB times were similar between groups, as were overall time to extubation, intensive care unit stay, and total length of hospital stay (Table 1).

\section{Hemodynamics and Endothelin Levels After Cardiopulmonary Bypass}

Absolute values for heart rate, mean arterial blood pressure, pulmonary artery pressure, and systemic and pulmonary vascular resistance, and plasma ET and ET-ARA values at baseline and the designated post-CPB time points are shown in Table 2 . Baseline hemodynamics were equivalent in patients randomized to the vehicle or 1 or $2 \mathrm{mg} / \mathrm{kg}$ ET-ARA groups. Pairwise comparison results are shown in Table 2, and the ANOVA results are summarized for hemodynamic variables in this paragraph. Heart rate increased as a function of post-CPB time $(\mathrm{F}=10.2, P=.001)$ and was higher in the ET-ARA groups at later post-CPB time points. Mean arterial pressure decreased at early post-CPB time points, and this was a significant time effect $(\mathrm{F}=6.68, P$ $=.001$ ). Pulmonary artery pressures tended to increase in the post-CPB periods, and a significant treatment effect on this hemodynamic value was observed $(\mathrm{F}=5.17, P=$ .007). Cardiac output was increased in the early postoperative time points in the ET-ARA groups. Systemic vascular resistance decreased in the post-CPB time periods with both time $(\mathrm{F}=5.03, P=.001)$ and treatment $(\mathrm{F}=4.10, P$ $=.018$ ) effects, and this parameter decreased to the greatest degree in the $2 \mathrm{mg} / \mathrm{kg}$ ET-ARA group. Pulmonary vascular resistance changed in a time-dependent manner post-CPB $(\mathrm{F}=2.20, P=.058)$. Plasma ET levels increased in the post-CPB period (F $=15.45, P=.001)$, and higher values were observed in the $2 \mathrm{mg} / \mathrm{kg}$ group. Plasma levels for the ET-ARA sitaxsentan immediately after infusion, at the 6hour time point, immediately after the second infusion at 12 hours, and at the 24-hour time point are shown in Table 2. At 6 hours after the first infusion of the ET-ARA, a significant reduction in plasma drug concentrations was observed. At 24 hours after the second ET-ARA infusion, drug levels were at minimal detectable levels, consistent with the clearance kinetics of this compound. ${ }^{26}$ Because a high degree of within-patient variation in systemic and pulmonary vascular resistance occurred at baseline and post-CPB time points, these indices were transformed as a function of time 0 to more carefully examine potential treatment effects. There were no significant differences in the relative change in systemic vascular resistance with respect to treatment (ANOVA, $\mathrm{F}=0.13, P=.88$ ). However, the relative change in pulmonary vascular resistance was significantly affected by treatment, with the greatest reduction in this parameter in the $2 \mathrm{mg} / \mathrm{kg}$ group at the late post-CPB time points (Figure 2).

\section{Adverse Events}

A total of 168 AEs were tabulated in the postoperative period, and a categoric distribution of these AEs is presented in Table 3 . The total number of AEs was not significantly different among the 3 groups $(P=.09)$. AEs were equally distributed across treatment groups with 1 exception: the hematologic/lymphatic category, for which a higher percentage was reported in the $2 \mathrm{mg} / \mathrm{kg}$ group. The preponderance of these AEs in the $2 \mathrm{mg} / \mathrm{kg}$ group (10) was secondary to low postoperative hematocrit that occurred in 5 patients as the result of increased perioperative blood loss. These AEs were adjudicated not to be study related. There were 18 serious adverse events (SAEs) reported. These SAEs included 3 patient deaths that occurred in the $1 \mathrm{mg} / \mathrm{kg}$ ET-ARA $(\mathrm{n}=2)$ and the $2 \mathrm{mg} / \mathrm{kg}$ ET-ARA $(\mathrm{n}=1)$ groups and that were considered unrelated to ET-ARA treatment after adjudication. One patient with a significantly low $(<30 \%)$ preoperative ejection fraction died of low cardiac output and respiratory failure on the second postoperative day. On review, this poor postoperative course may have been precipitated by a protamine reaction, thereby exacerbating the preexisting LV dysfunction. The second patient died of sudden cardiac arrest during a routine incentive spirometry session on 
TABLE 2. Hemodynamics at baseline and after cardiopulmonary bypass in patients randomized to vehicle or endothelin-A receptor antagonist sitaxsentan

\begin{tabular}{|c|c|c|c|c|c|}
\hline & \multirow[b]{2}{*}{ Baseline } & \multicolumn{4}{|c|}{ Post-CPB (h) } \\
\hline & & $\mathbf{0}$ & 6 & 12 & 24 \\
\hline \multicolumn{6}{|l|}{ Heart rate (beats/min) } \\
\hline Vehicle & $62.6 \pm 3.7$ & $77.8 \pm 2.9$ & $75.2 \pm 3.8$ & $78.5 \pm 5.6$ & $78.6 \pm 4.1$ \\
\hline $1 \mathrm{mg} / \mathrm{kg}$ ET-ARA & $63.6 \pm 2.0$ & $80.1 \pm 4.6$ & $85.1 \pm 6.4^{*}$ & $88.2 \pm 3.2^{*}$ & $91.7 \pm 6.6^{*}$ \\
\hline $2 \mathrm{mg} / \mathrm{kg}$ ET-ARA & $62.4 \pm 2.8$ & $84.5 \pm 5.2^{*}$ & $85.6 \pm 5.2^{*}$ & $84.5 \pm 5.5^{*}$ & $85.9 \pm 4.2^{*}$ \\
\hline \multicolumn{6}{|c|}{ Arterial pressure $(\mathrm{mm} \mathrm{Hg})$} \\
\hline Vehicle & $82.8 \pm 3.9$ & $72.5 \pm 3.7$ & $76.1 \pm 3.5$ & $72.9 \pm 2.8$ & $80.5 \pm 4.3$ \\
\hline $1 \mathrm{mg} / \mathrm{kg}$ ET-ARA & $80.7 \pm 4.8$ & $69.0 \pm 4.6$ & $75.3 \pm 3.0$ & $70.2 \pm 3.0$ & $80.9 \pm 2.3$ \\
\hline $2 \mathrm{mg} / \mathrm{kg}$ ET-ARA & $80.1 \pm 3.2$ & $71.9 \pm 4.0$ & $73.9 \pm 2.8$ & $72.6 \pm 1.6$ & $80.1 \pm 2.3$ \\
\hline \multicolumn{6}{|l|}{ Pulmonary artery } \\
\hline Vehicle & $20.4 \pm 1.4$ & $20.8 \pm 2.2$ & $23.8 \pm 2.3$ & $24.6 \pm 1.4$ & $22.9 \pm 1.5$ \\
\hline $1 \mathrm{mg} / \mathrm{kg}$ ET-ARA & $25.7 \pm 3.6$ & $19.3 \pm 2.4$ & $22.4 \pm 1.4$ & $22.1 \pm 2.0$ & $24.2 \pm 2.3$ \\
\hline $2 \mathrm{mg} / \mathrm{kg}$ ET-ARA & $25.3 \pm 4.2$ & $26.0 \pm 3.3$ & $28.4 \pm 3.2$ & $26.4 \pm 1.8$ & $26.6 \pm 2.4$ \\
\hline \multicolumn{6}{|l|}{ Cardiac output (L/min) } \\
\hline Vehicle & $4.4 \pm 0.3$ & $4.8 \pm 0.4$ & $5.2 \pm 0.4$ & $5.4 \pm 0.4$ & $5.3 \pm 0.5$ \\
\hline $1 \mathrm{mg} / \mathrm{kg}$ ET-ARA & $4.4 \pm 0.6$ & $5.5 \pm 0.7$ & $5.9 \pm 0.8^{*}$ & $6.8 \pm 0.7^{*}$ & $6.9 \pm 0.8^{*}$ \\
\hline $2 \mathrm{mg} / \mathrm{kg}$ ET-ARA & $4.3 \pm 0.2$ & $5.5 \pm 0.4$ & $6.1 \pm 0.4^{*}$ & $5.5 \pm 0.2$ & $5.6 \pm 0.4$ \\
\hline \multicolumn{6}{|c|}{$\begin{array}{l}\text { Systemic vascular } \\
\quad \text { resistance }\left(\text { dynes } / \mathrm{sec} / \mathrm{cm}^{-5}\right)\end{array}$} \\
\hline Vehicle & $1408 \pm 119$ & $1155 \pm 165$ & $1106 \pm 157$ & $962 \pm 98$ & $1192 \pm 158$ \\
\hline $1 \mathrm{mg} / \mathrm{kg}$ ET-ARA & $1359 \pm 210$ & $894 \pm 159$ & $1068 \pm 193$ & $761 \pm 71$ & $898 \pm 115$ \\
\hline $2 \mathrm{mg} / \mathrm{kg}$ ET-ARA & $1307 \pm 112$ & $960 \pm 89 *$ & $820.7 \pm 67^{*}$ & $897 \pm 46^{*}$ & $1015 \pm 86$ \\
\hline \multicolumn{6}{|c|}{$\begin{array}{l}\text { Pulmonary vascular resistance } \\
\left(\text { dynes } / \mathrm{sec} / \mathrm{cm}^{-5}\right)\end{array}$} \\
\hline Vehicle & $153.8 \pm 19.9$ & $123.5 \pm 20.7$ & $138.7 \pm 28.0$ & $146.8 \pm 21.6$ & $163.3 \pm 26.6$ \\
\hline $1 \mathrm{mg} / \mathrm{kg}$ ET-ARA & $213.0 \pm 65.3$ & $125.3 \pm 24.8$ & $144.6 \pm 15.2$ & $132.7 \pm 12.7$ & $125.5 \pm 22.3$ \\
\hline $2 \mathrm{mg} / \mathrm{kg}$ ET-ARA & $174.6 \pm 28.4$ & $175.8 \pm 26.6$ & $132.7 \pm 17.6$ & $136.6 \pm 17.5$ & $138.7 \pm 20.0$ \\
\hline \multicolumn{6}{|c|}{ Plasma ET-1 (fmol/mL) } \\
\hline Vehicle & $3.9 \pm 0.4$ & $5.5 \pm 0.8$ & $8.2 \pm 1.1^{*}$ & $8.6 \pm 1.1^{*}$ & $8.0 \pm 1.0^{*}$ \\
\hline $1 \mathrm{mg} / \mathrm{kg}$ ET-ARA & $3.7 \pm 0.3$ & $4.7 \pm 0.5$ & $7.2 \pm 1.3$ & $8.8 \pm 1.7^{*}$ & $8.3 \pm 1.0^{*}$ \\
\hline $2 \mathrm{mg} / \mathrm{kg}$ ET-ARA & $4.3 \pm 0.7$ & $4.1 \pm 0.5$ & $7.6 \pm 1.2$ & $10.4 \pm 1.6^{*}$ & $8.6 \pm 1.4^{*}$ \\
\hline \multicolumn{6}{|c|}{ Sitaxsentan levels $(\mu \mathrm{g} / \mathrm{mL})$} \\
\hline $1 \mathrm{mg} / \mathrm{kg}$ ET-ARA & N/A & $7.35 \pm 0.83$ & $0.06 \pm 0.01$ & $1.88 \pm 1.26$ & $0.06 \pm 0.01$ \\
\hline $2 \mathrm{mg} / \mathrm{kg}$ ET-ARA & N/A & $11.78 \pm 1.17 \dagger$ & $2.24 \pm 2.13$ & $8.63 \pm 3.24 \dagger$ & $0.09 \pm 0.01$ \\
\hline
\end{tabular}

$C P B$, Cardiopulmonary bypass; $E T$-ARA, endothelin-A receptor antagonist. Vehicle, $\mathrm{n}=10 ; 1 \mathrm{mg} / \mathrm{kg}, \mathrm{n}=9 ; 2 \mathrm{mg} / \mathrm{kg}, \mathrm{n}=10 . * P<.05$ vs baseline. $\dagger^{\dagger} P<.05 \mathrm{vs} 1 \mathrm{mg} / \mathrm{kg}$ ET-ARA.

postoperative day 3 (within 24 hours of anticipated hospital discharge). The third patient died of presumed cardiopulmonary failure 38 days postoperatively in an outlying facility. The other SAEs were cardiovascular (thromboembolic event, bleeding, $\mathrm{n}=8)$, pulmonary/infection $(\mathrm{n}=6)$, and gastrointestinal (ischemic bowel, $\mathrm{n}=1$ ). When the SAEs were considered as a composite, there were no significant differences among treatment groups (chi-square 1.59; $P=$ $.452)$.

\section{DISCUSSION}

Increased synthesis and release of the peptide ET- 1 occur in several cardiovascular disease states and bind to 2 predominant receptor subtypes: the ET-A and B receptors. The most studied effects are that of ET binding to the ETA receptor, which causes significant vasoconstriction, influ- ences excitation-contraction coupling processes, and modifies sympathetic efferent firing and chronotropy within the myocardium. ${ }^{1-8,20,27-31}$ In marked contrast, ET binding to the ET-B receptor mediates the release of nitric oxide and causes relaxation of vascular smooth muscle. , $^{1,2,7,16-18,21,32,33}$ In light of these differential effects, selective ET-ARAs have been developed and deployed in cardiovascular disease states such as pulmonary hypertension. ${ }^{16,18,22}$ Past studies have demonstrated that increased ET release occurs in patients after cardiac surgery requiring $\mathrm{CPB}$ and may contribute to a complex postoperative course. ${ }^{3,24,25,34}$ In an initial dose-ranging pilot study in patients undergoing elective CABG requiring $\mathrm{CPB}$, the ET-ARA antagonist sitaxsentan was well tolerated and caused a dose-dependent decrease in pulmonary vascular resistance in the post-CPB period. ${ }^{25}$ This initial study was performed in low-risk patients with 


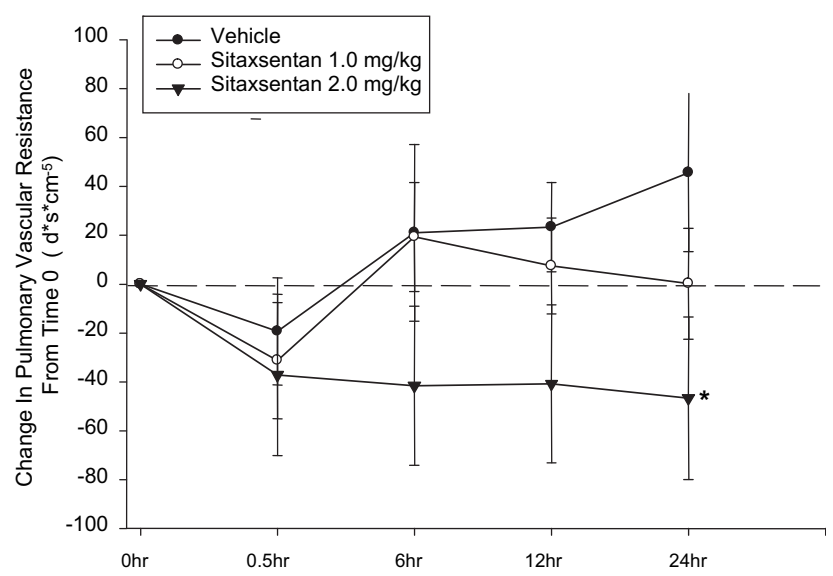

FIGURE 2. Changes in pulmonary vascular resistance, computed in absolute units, from time 0 (vehicle/ET-ARA infusion and separation from $\mathrm{CPB}$ ). In the early post-CPB period, an ET-ARA effect was observed for pulmonary vascular resistance (ANOVA, $\mathrm{F}=4.73, P=.01$ ). Pairwise comparisons showed a significantly lower pulmonary vascular resistance 24hours post-CPB ( $* P<.05$ vs vehicle).

respect to preexisting risk factors, such as LV function. However, patients with preexisting risk factors, such as LV systolic dysfunction and complex medical histories (ie, hypertension, diabetes, increased age), who present for cardiac surgery are those with a higher incidence of postoperative morbidity and mortality. ${ }^{9-15}$ Thus, if inhibition of the ET-A receptor is to be considered a viable therapeutic target in cardiac surgery, then an ET-ARA must be evaluated in higher-risk patients undergoing cardiac surgery. Accordingly, by using a blinded and randomized protocol, the present study infused vehicle or 1 or $2 \mathrm{mg} / \mathrm{kg}$ of the ET-ARA sitaxsentan in patients with preexisting LV dysfunction at the time of separation from CPB and at 12 hours postCPB. This initial study demonstrated that the ET-ARA could be used in high-risk patients and that the higher dose of sitaxsentan attenuated the degree of pulmonary vasoconstriction in the post-CPB period. This study adds to the growing body of evidence that inhibition of the ET-A receptor may be a viable therapeutic target in the context of cardiac surgery requiring $\mathrm{CPB}$.

Synthesis and release of the bioactive molecule ET occur within all cell types and organ systems, particularly within the cardiovascular system. ${ }^{16-20}$ Although the role of ET in systemic hypertension and heart failure has been the focus of both basic and clinical studies, ${ }^{17-19,28,33}$ the primary therapeutic target has been that of primary pulmonary hypertension. Specifically, oral formulations of both nonselective and ET-A subtype selective antagonists have been described to be efficacious in pulmonary hypertension. ${ }^{16,18,22}$ However, an oral formulation of an ET-ARA would not be of practical clinical use in an acute care setting, and therefore infusible formulations of selective ET-ARAs would be required. This laboratory has described basic and clinical studies using an intravenous formulation of the ET-ARA sitaxsen$\tan ^{24,25,35}$ These past studies demonstrated a significant reduction in pulmonary vascular resistance post-CPB. ${ }^{25,35}$ However, these studies were performed in the context of normal LV function, whereas a preponderance of patients may present for cardiac surgery with preexisting LV myocardial dysfunction and other comorbidities, such as diabetes. Previous work demonstrated that the density and distribution of myocardial ET-A receptor subtypes may be increased in LV dysfunction, and that the sensitivity of ET can be enhanced with diabetes. ${ }^{33,36,37}$ The present study was the first to demonstrate that an infusible ET-ARA used in patients with significant preexisting cardiac surgical risk factors influenced pulmonary vascular resistance in the early postoperative period. However, this study used only 1 highly selective ET-ARA, and therefore it remains to be established whether this is a class effect that can be achieved with other selective ET-ARAs.

In the present study, conventional hemodynamic monitoring was performed at prespecified intervals before and after vehicle or ET-ARA administration. In both the 1 and $2 \mathrm{mg} /$ $\mathrm{kg}$ ET-ARA groups, heart rate increased in the post-CPB period. This increased chronotropy with ET-ARA treatment does not seem to have been caused by a baroreceptor reflex response, because arterial blood pressure remained unchanged at these post-CPB time points. Rather, it has been reported that ET has a direct negative effect on chronotropy and that ET receptor inhibition has a positive chronotropic effect, likely because of local sympathetic effects on sinoatrial nodal cells. ${ }^{29-31}$ There are 2 important considerations regarding the potential positive chronotropic effect of the ET-ARA that was observed in the present study. First, the increased heart rate can significantly affect cardiac output and in turn influence the resistance calculations. Cardiac output was increased to the greatest degree in the ET-ARA groups in the postoperative period. Second, heart rate is an important determinant of myocardial oxygen demand, and therefore the chronotropic effect of ET-ARA infusion may not be a desirable effect in the early postoperative period. A past study by this laboratory demonstrated that exogenous ET caused potent vasoconstriction of vascular conduits used in CABG, and that selective ET-ARAs inhibited this effect. ${ }^{3}$ Thus, although not directly measured in the present study, infusion of an ET-ARA in the early post-CPB period may have several effects on myocardial oxygen demand and blood flow.

In general terms, baseline hemodynamics were similar across the randomized groups, but there was some intrinsic variability in these measurements likely because of varying degrees of cardiopulmonary compromise in patients. Because the true intervention used in this study did not occur until vehicle/ET-ARA infusion and separation from CPB, time 0 was the point that was used as the index event. Accordingly, the relative changes in key hemodynamic 
TABLE 3. Adverse events in high-risk patients after cardiopulmonary bypass randomized to vehicle or endothelin-A receptor antagonist sitaxsentan

\begin{tabular}{|c|c|c|c|c|c|c|}
\hline \multirow[b]{2}{*}{ Adverse event } & \multirow[b]{2}{*}{ Vehicle } & \multicolumn{2}{|c|}{ Sitaxsentan } & \multirow[b]{2}{*}{ Total } & \multirow[b]{2}{*}{ Chi-square } & \multirow[b]{2}{*}{$P$ value } \\
\hline & & $1 \mathrm{mg} / \mathrm{kg}$ & $2 \mathrm{mg} / \mathrm{kg}$ & & & \\
\hline Cardiovascular & 12 & 20 & 17 & 49 & 2 & .368 \\
\hline$\%$ & $24 \%$ & $41 \%$ & $35 \%$ & $100 \%$ & & \\
\hline Pulmonary & 3 & 4 & 8 & 15 & 2.8 & .246 \\
\hline$\%$ & $20 \%$ & $27 \%$ & $53 \%$ & $100 \%$ & & \\
\hline Neurologic & 2 & 0 & 0 & 2 & 0.5 & .779 \\
\hline$\%$ & $100 \%$ & $0 \%$ & $0 \%$ & $100 \%$ & & \\
\hline Urinary & 2 & 0 & 3 & 5 & 1.0 & .606 \\
\hline$\%$ & $40 \%$ & $0 \%$ & $60 \%$ & $100 \%$ & & \\
\hline Gastrointestinal & 9 & 8 & 8 & 25 & 0.1 & .961 \\
\hline$\%$ & $36 \%$ & $32 \%$ & $32 \%$ & $100 \%$ & & \\
\hline Hepatic & 0 & 3 & 1 & 4 & 1.6 & .449 \\
\hline$\%$ & $0 \%$ & $75 \%$ & $25 \%$ & $100 \%$ & & \\
\hline Musculoskeletal & 1 & 7 & 5 & 13 & 4.3 & .116 \\
\hline$\%$ & $8 \%$ & $54 \%$ & $38 \%$ & $100 \%$ & & \\
\hline Genitourinary/gynecologic & 0 & 0 & 0 & 0 & $\mathrm{n} / \mathrm{a}$ & $\mathrm{n} / \mathrm{a}$ \\
\hline$\%$ & $0 \%$ & $0 \%$ & $0 \%$ & $0 \%$ & & \\
\hline Endocrine/metabolic & 1 & 1 & 5 & 7 & 4.6 & .102 \\
\hline$\%$ & $14 \%$ & $14 \%$ & $71 \%$ & $100 \%$ & & \\
\hline Immunologic/allergic & 0 & 1 & 0 & 1 & 2.3 & .316 \\
\hline$\%$ & $0 \%$ & $100 \%$ & $0 \%$ & $100 \%$ & & \\
\hline Hematologic/lymphatic & 1 & 4 & 10 & 15 & 8.4 & .015 \\
\hline$\%$ & $7 \%$ & $27 \%$ & $67 \%$ & $100 \%$ & & \\
\hline Psychologic/behavioral & 3 & 4 & 7 & 14 & 1.9 & .395 \\
\hline$\%$ & $21 \%$ & $29 \%$ & $50 \%$ & $100 \%$ & & \\
\hline HEENT & 1 & 0 & 0 & 1 & 2.0 & .374 \\
\hline$\%$ & $100 \%$ & $0 \%$ & $0 \%$ & $100 \%$ & & \\
\hline Infection & 3 & 0 & 2 & 5 & 1.0 & .606 \\
\hline$\%$ & $60 \%$ & $0 \%$ & $40 \%$ & $100 \%$ & & \\
\hline Fever & 0 & 3 & 4 & 7 & 1.8 & .417 \\
\hline$\%$ & $0 \%$ & $43 \%$ & $57 \%$ & $100 \%$ & & \\
\hline Dermatologic & 0 & 3 & 2 & 5 & 1.0 & .606 \\
\hline$\%$ & $0 \%$ & $60 \%$ & $40 \%$ & $100 \%$ & & \\
\hline
\end{tabular}

HEENT, Head, eyes, ears, nose, and throat.

variables were computed from this index time point. From this analysis, the most significant treatment effect was that observed with respect to pulmonary vascular resistance in the later post-CPB time points. One potential contributory factor for the relative changes in pulmonary vascular resistance observed in the ET-ARA groups was an increase in cardiac output. However, the greatest increase in cardiac output was observed in the $1 \mathrm{mg} / \mathrm{kg}$ ET-ARA group, whereas the greatest reduction in pulmonary vascular resistance was observed in the $2 \mathrm{mg} / \mathrm{kg}$ ET-ARA group, which is consistent with the pharmacologic effects of ET-ARAs in general and our past reports using this infusible ETARA. ${ }^{25}$ In addition, the greatest reduction in systemic vascular resistance was observed in the $2 \mathrm{mg} / \mathrm{kg}$ ET-ARA group. However, more sensitive and direct effects on vascular compliance and the potential effects of ET-ARA were not evaluated in the present study. It has been clearly demon- strated that ET receptor inhibition causes a direct vasodilatory effect within the pulmonary vasculature. ${ }^{16-18}$ Taken together, the mechanisms that underlie the effects of ET-ARA on pulmonary vascular resistance were likely combinatorial and included increased cardiac output and direct effects on pulmonary vascular tone.

The current study predicated the 2 doses of the ET-ARA on the results of past dose ranges in patients undergoing elective CABG with normal LV ejection fraction. ${ }^{25}$ The rationale for the timing of the ET-ARA infusions was based on previous observations regarding the temporal dynamics of ET release in the post-CPB period and the pharmacokinetics of ET-ARA itself. ${ }^{24-26,34}$ Specifically, the release of ET postCPB seems to occur in a biphasic manner in which an initial surge occurs immediately after separation from CPB and a second peak occurs at approximately 12 hours after $\mathrm{CPB}{ }^{24,34}$ Thus, the present study was designed to target 
both of these phases of ET release through bolus infusions of the ET-ARA immediately post-CPB and 12 hours post$\mathrm{CPB}$. Consistent with the pharmacokinetics of sitaxsentan, plasma levels of this ET-ARA were detectable at 6 hours after bolus infusion of the $2 \mathrm{mg} / \mathrm{kg}$ dose, but were nominal by 12 hours after bolus infusion. ${ }^{26}$ In light of this, the direct pharmacologic effects of the ET-ARA that were observed in the present study would not likely persist beyond 12 hours after dosing. Thus, because steady-state hemodynamics and pulmonary vascular resistance did not abruptly increase at the 24-hour post-CPB time point, a significant autoregulatory or pharmacologic "rebound effect" may not be operative with this dosing regimen. However, several issues warrant consideration for the pharmacologic use of this ET-ARA in cardiac surgery. First, longer monitoring periods will be necessary to fully examine the hemodynamic effects of the ET-ARA infusion protocol used in the present study. Second, a larger prospective study is necessary to determine whether the effects of this infusible ET-ARA cause dose-dependent effects on pulmonary vascular resistance and whether $2 \mathrm{mg} / \mathrm{kg}$ of the ET-ARA is a maximally effective dose in a high-risk cardiac surgical population.

The present study examined plasma ET levels in patients with preexisting LV dysfunction preoperatively and after $\mathrm{CPB}$. The first important observation from these measurements was that preoperative, steady-state plasma ET levels were higher in patients with preexisting LV systolic dysfunction when compared with preoperative ET levels measured under identical conditions in an age-matched cohort of patients with normal LV systolic function. ${ }^{24,25}$ Increased plasma ET levels have been reported in patients with significant heart failure. ${ }^{17-19,33}$ Thus, the increased plasma ET levels are likely reflective of the pathophysiologic consequences of LV dysfunction. Although remaining speculative, the present study provides evidence to suggest that preoperative measurements of plasma ET may serve as a biomarker for patients at increased risk for ET-mediated events, such as increased pulmonary vascular resistance, in the postCPB period. A larger prospective study will be necessary to directly address this issue. Consistent with past reports, ${ }^{24,25,34,35}$ plasma ET levels increased significantly in the post-CPB period, which is likely the result of increased synthesis and spillover from interstitial compartments, such as the myocardium. ${ }^{33,34}$ In the ET-ARA groups, plasma ET levels were increased to the greatest degree in the post-CPB period. The reasons for the increased circulating levels of ET with infusion of the ET-ARA are likely 2fold. (1) Inhibition of the ET-A receptor likely interrupts a receptor-transduction feedback pathway and thereby may induce increased synthesis and release of ET. (2) Occupancy of the ET-A receptor with the antagonist will displace bound $\mathrm{ET}$ and therefore cause a reflective increase in plasma levels. The highest levels of ET occurred 12 hours after CPB, when a second infusion of the ET-ARA was delivered, which would lend support for the displacement of bound ET to cognate ET-A receptors. Although the increased plasma levels of ET in the late post-CPB period in the ET-ARA groups is likely a summation of these factors, the increased plasma ET is evidence for a pharmacologic effect of the ET-ARA.

Because sitaxsentan is a potent and selective ET-ARA, the increased levels of ET may cause heightened binding and activation of the ET-B receptor. The increased activation of the ET-B receptor in turn may cause increased nitric oxide release and vascular smooth muscle relaxation, particularly in the pulmonary vasculature. Thus, a potential indirect pathway by which ET-ARA infusion facilitated a reduction in pulmonary vascular resistance in the post-CPB period was through increased and unopposed activation of the pulmonary ET-B receptor. The selective reduction in pulmonary vascular resistance may hold particular relevance in patients with preexisting right ventricular (RV) failure or in whom RV failure develops perioperatively. Specifically, a relative reduction in $\mathrm{RV}$ afterload may be beneficial in the early postoperative period, particularly because RV failure is not an uncommon occurrence in the context of cardiac surgery. ${ }^{36,37}$ However, this issue was not directly addressed in the present study.

The present study was the first to use a selective ET-ARA in patients undergoing cardiac surgery with significant preoperative risk factors. Because of the advanced age and poor LV systolic performance of these patients, it was not surprising there were a number of AEs encountered during the course of the study. One of the first major limitations of this study was the small sample size, which in turn can result in a disproportionate number of patients with greater preoperative risk profiles randomized to 1 treatment group. Indeed, a significantly greater number of patients randomized to the $2 \mathrm{mg} / \mathrm{kg}$ ET-ARA group presented for reoperation and had increased diuretic dependency. All 5 reoperations were randomized to an ET-ARA group, 4 of these to the $2 \mathrm{mg} / \mathrm{kg}$ group. The increased incidence of low hematocrit/hemoglobin in the early postoperative period in the $2 \mathrm{mg} / \mathrm{kg}$ ET-ARA group may have been due in part to the increased perioperative bleeding that can occur in reoperation. Speculatively, diuretic dependence may be an indicator of more advanced heart failure. Notably, despite a higher preoperative risk profile in the $2 \mathrm{mg} / \mathrm{kg}$ ET-ARA group, the total number of AEs and SAEs was not significantly increased. The 3 patients who died in this study had a significant preoperative risk, and their deaths were adjudicated not to be associated with ET-ARA treatment. Furthermore, the statistical analysis suggests the deaths that occurred in the ET-ARA groups were strictly due to chance. Nevertheless, these outcomes coupled with the limited sample size of this initial feasibility study warrant a note of caution that can only be further addressed by a larger prospective study. 


\section{CONCLUSIONS}

In patients with preexisting LV systolic dysfunction, increased ET-A receptor activation likely contributes to changes in hemodynamic profiles after cardiac surgery requiring $\mathrm{CPB}$, and therefore constitutes a viable therapeutic target.

The authors thank Theresa A. Brinsa for assistance with data analysis.

\section{References}

1. Krum H, Liew D. Current status of endothelin-1 blockade for the treatment of cardiovascular and pulmonary vascular disease. Curr Opin Investig Drugs. 2003;4: 298-302.

2. Miyauchi T, Masaki T. Pathophysiology of endothelin-1 in the cardiovascular system. Annu Rev Physiol. 1999;61:391-415.

3. Bond BR, Dorman BH, Clair MJ, Walker CA, Pinosky ML, Reeves ST, et al. Endothelin-1-1 during and after cardiopulmonary bypass: association to graft sensitivity and postoperative recovery. J Thorac Cardiovasc Surg. 2001;122:358-64.

4. Ivey ME, Osman N, Little PJ. Endothelin-1-1 signalling in vascular smooth muscle: pathways controlling cellular functions associated with atherosclerosis. Atherosclerosis. 2008; 199:237-47.

5. Pollock JS, Pollock DM. Endothelin-1 and NOS1/nitric oxide signaling and regulation of sodium homeostasis. Curr Opin Nephrol Hypertens. 2008;17:70-5.

6. Mohácsi A, Magyar J, Tamás B, Nánási PP. Effects of endothelin-1s on cardiac and vascular cells: new therapeutic target for the future? Curr Vasc Pharmacol. 2004;2:53-63.

7. D'Orléans-Juste P, Labonté J, Bkaily G, Choufani S, Plante M, Honoré JC. Function of the endothelin-1(B) receptor in cardiovascular physiology and pathophysiology. Pharmacol Ther. 2002;95:221-38.

8. Giannessi D, Del Ry S, Vitale RL. The role of endothelin-1s and their receptors in heart failure. Pharmacol Res. 2001;43:111-26.

9. Ikonomidis JS, Rao V, Weisel RD, Hayashida N, Shirai T. Myocardial protection for coronary bypass grafting: the Toronto Hospital perspective. Ann Thorac Surg. 1995;60:824-32.

10. Phillips HR, Carter JE, Okada RD, Levine FH, Boucher CA, Osbakken M, et al. Serial changes in left ventricular ejection fraction in the early hours after aortocoronary bypass grafting. Chest. 1983;83:28-34.

11. Svircevic V, Nierich AP, Moons KG. Brandon Bravo Bruinsma GJ, Kalkman CJ, van Dijk D. Fast-track anesthesia and cardiac surgery: a retrospective cohort study of 7989 patients. Anesth Analg. 2009;108:727-33.

12. Zingone B, Gatti G, Rauber E, Tiziani P, Dreas L, Pappalardo A, et al. Early and late outcomes of cardiac surgery in octogenarians. Ann Thorac Surg. 2009;87:71-8.

13. Mehta RH, Hafley GE, Gibson CM, Harrington RA, Peterson ED, Mack MJ, et al. Project of Ex-vivo Vein Graft Engineering via Transfection (PREVENT)-IV Investigators. Influence of preoperative renal dysfunction on one-year bypass graft patency and two-year outcomes in patients undergoing coronary artery bypass surgery. J Thorac Cardiovasc Surg. 2008;136:1149-55.

14. Woods SE, Eppley C, Engel A. The influence of diabetes mellitus in patients undergoing coronary artery bypass graft surgery: a prospective cohort study. Am Surg. 2008;74:839-44.

15. Scrutinio D, Giannuzzi P. Comorbidity in patients undergoing coronary artery bypass graft surgery: impact on outcome and implications for cardiac rehabilitation. Eur J Cardiovasc Prev Rehabil. 2008;15:379-85.

16. Opitz CF, Ewert R, Kirch W, Pittrow D. Inhibition of endothelin-1 receptors in the treatment of pulmonary arterial hypertension: does selectivity matter? Eur Heart J. 2008;29:1936-48.

17. Kirkby NS, Hadoke PW, Bagnall AJ, Webb DJ. The endothelin-1 system as a therapeutic target in cardiovascular disease: great expectations or bleak house? $\mathrm{Br} \mathrm{J}$ Pharmacol. 2008;153:1105-19.

18. Dhaun N, Pollock DM, Goddard J, Webb DJ. Selective and mixed endothelin-1 receptor antagonism in cardiovascular disease. Trends Pharmacol Sci. 2007;28: 573-9.
19. Kalra PR, Moon JC, Coats AJ. Do results of the ENABLE (Endothelin-1 Antagonist Bosentan for Lowering Cardiac Events in Heart Failure) study spell the end for non-selective endothelin-1 antagonism in heart failure? Int J Cardiol. 2002;85: 195-7.

20. Dorman BH, New RB, Bond BR, Mukherjee R, Mukhin YV, McElmurray JH, et al. Myocyte endothelin-1 exposure during cardioplegic arrest exacerbates contractile dysfunction after reperfusion. Anesth Analg. 2000;90:1080-5.

21. Dupuis J, Goresky CA, Fournier A. Pulmonary clearance of circulating endothelin-1-1 in dogs in vivo: exclusive role of ETB receptors. J Appl Physiol. 1996;81: 1510-5.

22. Barst RJ, Langleben D, Badesch D, Frost A, Lawrence EC, Shapiro S, et al. STRIDE-2 Study Group. Treatment of pulmonary arterial hypertension with the selective endothelin-1-A receptor antagonist sitaxsentan. I Am Coll Cardiol. 2006;47:2049-56.

23. Benza RL, Barst RJ, Galie N, Frost A, Girgis RE, Highland KB, et al. Sitaxsentan for the treatment of pulmonary arterial hypertension: a 1-year, prospective, open-label observation of outcome and survival. Chest. 2008;134: 775-82.

24. Ford RL, Mains IM, Hilton EJ, Reeves ST, Stroud RE, Crawford FA Jr, et al. Endothelin-1-A receptor inhibition after cardiopulmonary bypass: cytokines and receptor activation. Ann Thorac Surg. 2008;86:1576-83.

25. Ikonomidis JS, Hilton EJ, Payne K, Harrell A, Finklea L, Clark L, et al. Selective endothelin-1-A receptor inhibition after cardiac surgery: a safety and feasibility study. Ann Thorac Surg. 2007;83:2153-61.

26. Wu C, Decker ER, Biok N, Bui H, You TJ, Wang J, et al. Discovery, modeling, and human pharmacokinetics of N-(2-acetyl-4-6-dimethylphenyl)-3-(3,4-dimethylisoxazaol-5-ylsulfamoyl)thiophene-2-carboxamide (TBC3711), a second generation, ETA selective, and orally bioavailable endothelin-1 antagonist. $J$ Med Chem. 2004;47:1969-86.

27. Goldberg AT, Bond BR, Mukherjee R, New RB, Zellner JL, Crawford FA Jr, et al. Endothelin-1 receptor pathway in human left ventricular myocytes: relation to contractility. Ann Thorac Surg. 2000;69:711-6.

28. Thomas PB, Liu EC, Webb ML, Mukherjee R, Hebbar L, Spinale FG. Exogenous effects and endogenous production of endothelin-1 in cardiac myocytes: potential significance in heart failure. Am J Physiol. 1996;271(6 Pt 2):H2629-37.

29. Souza HC, Terzini GC, da Silva VJ, Martins-Pinge MC, Salgado HC, Salgado MC. Increased cardiac sympathetic drive and reduced vagal modulation following endothelin-1 receptor antagonism in healthy conscious rats. Clin Exp Pharmacol Physiol. 2008;35:751-6.

30. Ono K, Masumiya H, Sakamoto A, Christé G, Shijuku T, Tanaka H, et al. Electrophysiological analysis of the negative chronotropic effect of endothelin-1-1 in rabbit sinoatrial node cells. J Physiol. 2001;537(Pt 2):467-88.

31. Beaulieu P, Lambert C. Peptidic regulation of heart rate and interactions with the autonomic nervous system. Cardiovasc Res. 1998;37:578-85.

32. Johnström P, Fryer TD, Richards HK, Harris NG, Barret O, Clark JC, et al. Positron emission tomography using $18 \mathrm{~F}$-labelled endothelin-1-1 reveals prevention of binding to cardiac receptors owing to tissue-specific clearance by ET B receptors in vivo. Br J Pharmacol. 2005;144:115-22.

33. Ergul A, Grubbs AL, Zhang Y, Joffs C, Sample JA, King MK, et al. Expression and activity of pulmonary endothelin-1 converting enzyme in heart failure: relation to endothelin-1 biosynthesis and receptor distribution. J Card Fail. 2001;7: 84-91.

34. Multani MM, Ikonomidis JS, Kim PY, Miller EA, Payne KJ, Mukherjee R, et al. Dynamic and differential changes in myocardial and plasma endothelin-1 in patients undergoing cardiopulmonary bypass. J Thorac Cardiovasc Surg. 2005; 129:584-90.

35. Joffs C, Walker CA, Hendrick JW, Fary DJ, Almany DK, Davis JN, et al. Endothelin-1 receptor subtype A blockade selectively reduces pulmonary pressure after cardiopulmonary bypass. J Thorac Cardiovasc Surg. 2001;122: 365-70.

36. Yadav H, Unsworth B, Fontana M, Diller GP, Kyriacou A, Baruah R, et al. Selective right ventricular impairment following coronary artery bypass graft surgery. Eur J Cardiothorac Surg. 2009 Sep 14 [Epub ahead of print].

37. Haddad F, Couture P, Tousignant C, Denault AY. The right ventricle in cardiac surgery, a perioperative perspective: II. Pathophysiology, clinical importance, and management. Anesth Analg. 2009;108:422-33. 